\title{
La tradición medieval y el realismo político moderno en el teatro de Calderón de la Barca
}

\author{
The medieval tradition and the modern political \\ realism in the theater of Calderón de la Barca
}

\begin{tabular}{c} 
JULIO JUAN RUIZ \\
\hline Universidad Nacional de Mar del Plata, Argentina. \\
Juliojro7@yahoo.com.ar
\end{tabular}

\section{RESUMEN}

En la España del Siglo de Oro, el proceso de secularización política estuvo acompañado por resabios de la tradición medieval. Por esta razón, al realismo político moderno, basado en la doctrina de Nicolás Maquiavelo, se opuso la cosmovisión política medieval, subordinada a los lineamientos de la teología. En este sentido, el teatro barroco fue un espacio privilegiado, pues a diferencia del tratado teológico o filosófico, signado por la ortodoxia doctrinal, la escena, si bien estuvo vigilada por la censura, posibilitó un incipiente diálogo entre la tradición y el pensamiento político moderno. En el presente trabajo nos proponemos examinarlo en tres obras de Pedro Calderón de la Barca.

Palabras clave: Tradición, modernidad, poder, España, Calderón.

\begin{abstract}
In the Spanish Golden Age, the process of political secularization was accompanied by remnants of the medieval tradition. For this reason, the modern political realism, based on the doctrine of Nicolás Maquiavelo, opposed the medieval political worldview, subject to the guidelines of theology. In this sense, the baroque theater was a privileged, for unlike the philosophical or theological treatise, marked by doctrinal orthodoxy the scene, while was controlled by censorship, allowed an incipient
\end{abstract}


dialogue between tradition and modern political though. In this paper, we propose to examine three plays of Pedro Calderón de la Barca.

Keywords: Tradition, modernity, power, Spain, Calderón.

Recibido: 21.02.2013. Aceptado: 05.04.2013.

\section{INTRODUCCIÓN}

Z 1 teórico norteamericano Marshall Berman señaló, como primera fase de la Modernidad, el período que se extiende desde el comienzo del siglo XVI hasta fines del XVIII. En este segmento de la historia, las personas tuvieron "poca o mala sensación de pertenecer a un público o comunidad moderna en el seno de la cual pudieran compartir sus esfuerzos y esperanzas" (2008: 2).

A su vez, esta época de cuestionamientos constituyó un espacio privilegiado para examinar el legado de la tradición medieval ante los nuevos horizontes. En este sentido, el ámbito del poder estuvo signado por el advenimiento del realismo político, cuyas bases fueron construidas por Nicolás Maquiavelo, quien independizó este ámbito de la religión, de la ética y del derecho. De este modo, su doctrina contrastó con la cosmovisión medieval, signada por lo teológico. En este sentido, el teatro fue un espacio privilegiado para debatir doctrinas políticas opuestas, tal como lo comprobamos en el teatro de Calderón. Esta realidad llevó al crítico Antonio Regalado (1995) a expresar que el vate español careció de un pensamiento político propio. Sin embargo, si nos detenemos en sus textos, observamos que, si bien nos encontramos con doctrinas antagónicas, éstas se manifiestan en una relación dialéctica, cuya síntesis es un pensamiento marcado por firmes convicciones éticas, lo cual demuestra que el dramaturgo español fue un pensador profundo, cuya cosmovisión política estaba subordinada a la moral y al derecho natural, tal como lo planteaba el pensamiento de Suárez, cuyos textos analizó en el Colegio Imperial de los Jesuitas de Madrid, donde se formó. A este pensamiento ético, lo podemos constatar en sus tragedias; así, por ejemplo, En la vida es sueño, Segismundo accede al poder después de una conversión espiritual, donde la pasión fue sometida a los dictámenes de la razón. De este modo, emergió un modelo de príncipe estoico, quien demostró que pudo dominarse a sí mismo al renunciar a su amor por Rosaura, y al perdonar a su padre. Predominó, pues, un modelo de gobernante, 
cuyo accionar estaba subordinado a la moral, como lo esbozaban los Espejos de Principes medievales.

Debemos tener en cuenta que el filósofo alemán Guillermo F. Hegel utilizó el concepto de modernidad para referirse a acontecimientos como el Renacimiento y la Reforma, los que se produjeron alrededor del 1500. En este sentido, señala J. Habermas (2012) que "el concepto profano de época moderna expresa la convicción de que el futuro ha empezado ya: significa la época que vive orientada hacia el futuro" (2012: 15). Esta concepción se afianzó con los planteamientos estéticos del siglo XVIII (la querella entre antiguos y modernos), y, fundamentalmente, en el siglo XIX con la estética de Baudelaire. En efecto, para el escritor francés, la obra de arte ocupaba un punto de intersección entre dos ejes: la actualidad y la eternidad. De este modo, se produjo un desgarramiento al cortar los lazos con la tradición. Igual actitud estuvo presente en la Ilustración, tal como lo señaló Michel Foucault (1996), quien, al analizar el famoso texto de Kant, ¿Qué es la Ilustración?, señaló que, para esta corriente filosófica, la modernidad "[...] ya no es una relación longitudinal con los antiguos, sino que se podría llamar una relación "sagital" con su propia actualidad" (1996: 71). Así, se manifestó un hiato infranqueable entre la actualidad y el pasado; es decir, entre la Modernidad y la Tradición. Esta característica no se manifestó en los albores de la Modernidad Española, pues, como ya lo señaláramos, ésta mantuvo un diálogo no sólo con la tradición medieval, sino con la grecolatina, tal como lo comprueba la influencia que tuvieron autores como Séneca en la literatura del período Áureo. Asimismo, el mismo proceso de secularización política evidenció esta realidad, porque en España pervivió la tradición política medieval. El realismo político podía esbozar las estrategias adecuadas para conquistar y consolidad el poder del gobernante, pero no podía dictaminar sobre qué era el bien y el mal, como sí podía hacerlo la teología. Por este motivo, la doctrina de Nicolás Maquiavelo, que independizó la política de la moral y la religión fue anatematizada. A su vez, la síntesis entre la moral y la filosofía política fue realizada por Thomas Hobbes. En este sentido, Leo Strauss (2006) señaló que solo él fue “[...] quien formuló la pregunta fundamental por la vida justa del hombre y el ordenamiento justo de la sociedad" (2006: 26).

En el presente trabajo nos proponemos analizar la presencia de la tradición medieval y del realismo político moderno en tres obras de Calderón de la Barca, las que, en cierto modo, dan cuenta del rico debate que se produjo en la Modernidad. 


\section{LA TRADICIÓN MEDIEVAL EN EL NUEVO PALACIO DEL RETIRO}

Durante los siglos XV y XVII se desarrolló en España un proceso de secularización caracterizado por el advenimiento de una nueva forma jurídica de organización: el Estado Moderno. Sin embargo, en este proceso, tal como se dio en la península "hay que aceptar la presencia de dos sectores, uno secularizado y otro de tradición religiosa" (Maravall, 1970: 64). Por esta razón, este período debe ser examinado cuidadosamente a partir del estudio de las características políticas más salientes de la Edad Media en España. Así, en el Alto Medievo los reyes españoles no desempeñaron una función cuasi sacerdotal, como en el resto de Europa, tal como se expone en la obra de Ernst Kantorowicz (1985): Los dos cuerpos del rey. Pese al indiscutible rigor científico, no nos parece pertinente aplicar su análisis sobre el poder en la Alta Edad Media al poder de los reinos españoles, porque el monarca, para ser obedecido, no necesitó legitimarse en la fusión entre la Gracia y La naturaleza humana (Maravall, 1970). No por esto se debe subestimar la influencia que tuvo la religión; por el contrario, ésta cumplió un papel trascendental, como lo podemos constatar, pese a los siglos transcurridos, en $E l$ nuevo Palacio del Retiro de Calderón, donde se asentaron las bases del poder sobre basamentos teológicos.

Así, ya desde el comienzo, el auto sacramental, en su Loa, hace referencia al eje central del género, la eucaristía, mediante un diálogo sutil, que fue entablado entre dos personajes alegóricos, la vida práctica y la contemplativa. Este intercambio se inicia con una pregunta simple: "quién me dirá, quién me dirá, dónde hallaré el maná?”; a la cual, el Retiro, personificación alegórica del palacio destinado al placer real, inmediatamente responde: "En mi hermoso sitio está" (Calderón, 1969a: 133). Tal como ocurría en la fuga barroca que, luego de un tema muy simple, la línea melódica se bifurcaba en un complejo contrapunto, en el auto, tras esta pregunta se da comienzo a una aguda disquisición teológica, que versó sobre la diferencia ontológica entre el ángel y el hombre. En efecto, mientras que el ser celestial goza "de la caridad / perfecta, y unión con Cristo, / le ve en su gloria inmortal, / y le goza sin la fe", el hombre hasta alcanzar la "contemplación beatífica" se "une con Cristo, y el Pan / como Sacramente come" (Calderón, 1969a: 133). A través de esta comparación se afirmaba el dogma de la transustanciación. Así, pues, la sencilla pregunta que dio inicio al auto adquiere una dimensión precisa, pues Cristo, el maná, "el Buen Pastor en el Buen Retiro está".

Luego del introito teológico, comienza un diálogo entre el judaísmo, en 
plena diáspora, y el hombre sobre los hitos más importantes de la historia sagrada, y donde se marca el tránsito de la Ley natural a la escrita, y de ésta a la Ley de la gracia; es decir, del decálogo de Moisés a la ley de Cristo, la de la Gracia, desconocida por el pueblo hebreo. Seguidamente, el peregrino alcanzó a vislumbrar que, el Buen Retiro, es "la hermosa y rica / triunfante Jerusalén, / para su divina Esposa, / que es de la Gracia la ley" (Calderón, 1969a: 139). Sin embargo, el recinto real, asiento del cristianismo, está basado en la tradición hebrea, porque "se fundó el NUEVO PALACIO / pues son sus piedras los diez / Mandamientos, que tu pueblo / en el decálogo lee" (Calderón, 1969a: 139). Si bien es el mismo decálogo, "los leyó Moisés / en hebreo, y hoy aquí / están en latín, porque / San Jerónimo tradujo / su letra" (Calderón, 1969a: 139).

A su vez, la presencia del santo medieval pone de manifiesto la principal fuente en que, durante el Medievo, se legitimó el poder: la Biblia. En efecto, al realizar su traducción, San Jerónimo usó términos de la administración, del foro romano, y el léxico empleado por los filósofos y teólogos de su época, no el arcaico latín ciceroniano. De esta manera, trasladó a la mentalidad latina un texto que, en su forma hebrea o griega, pertenecía a una realidad social y política distinta. Así, por su familiaridad lingüística, se transformó en el vademécum de la Alta Edad Media, al ser consultado para buscar soluciones a problemas diferentes. Esta popularidad posibilitó la "aplicación directa o indirecta de temas bíblicos al gobierno medieval" (Ullmann, 2003: 107). En este sentido, uno de los textos más significativos fue el que narra el juicio de Cristo ante el procurador romano y gobernador de Judea, Poncio Pilatos. Durante el proceso, El Salvador le respondió al magistrado, Jn. 19, 11: "no tendrías ningún poder sobre mí, si no se te hubiera dado de arriba". En base a esta respuesta, se construyó la concepción descendente del poder, que iba de Dios al rey. Esta concepción, en el Texto Sagrado, esta diseminada en varios libros. Así, por ejemplo, en Sabiduría 6,3 se afirma la potestad del Creador: "porque Dios os ha dado el poder y el Altísimo la sabiduría, / a quien quiere se lo da". Asimismo, el receptor de este poder no tiene ningún derecho, pues lo goza por la Gracia divina. Esta última expresión es clave para comprender los fundamentos del poder medieval. En efecto, a través de la Gracia se estableció el vínculo entre el rey y Dios. Sin embargo, esta concepción no hubiese sido posible sin la labor de mediación que cumplió el texto de San Jerónimo. Así, la Vulgata moldeó la mentalidad medieval al entrelazar el romanismo secular y la Biblia. Ecos de ésta se encuentran en $E l$ nuevo Palacio del Retiro.

En el auto calderoniano se hizo hincapié en la Nueva Ley, porque "la ley 
de Gracia viene llena de placer / al NUEVO PALACIO REAL" (Calderón, 1969a: 140). Por la nueva ley, el ser humano reconoce lo que es como un don divino, tal como lo explicó San Pablo, en 1 Cor, 15, 10: "mas por la gracia de Dios soy lo que soy". A través del texto paulino podemos inferir el fundamento del gobierno en la Edad Media: Dios, por medio de su Gracia da el poder al rey, su elegido, quien lo goza sin ningún merecimiento. Esto significa que lo detentaba sólo por gozar de la benevolencia divina, es decir, de su placere. A su vez, esta concepción teocrática también sirvió para legitimar la relación entre el rey y sus súbditos, porque éstos gozan de su favor, como él de la benevolencia de Dios. Por el contrario, su pérdida, la indignatio regis, por su gravedad, conducía a la desgracia. Así, en la Biblia, ésta era asimilada a la muerte civil, es decir, a la pérdida de todo derecho, tal como lo constatamos en Prov. 16,14: "el furor del rey es mensajero de la muerte, / mas un hombre sabio le apacigua".

El par gracia / desgracia está sutilmente desplegado, pues relaciona la caída de Adán con la gracia que gozaba el valido de Felipe IV, el Conde-Duque de Olivares. No obstante se marca una diferencia histórica sustancial, como lo recordaba el Hombre, alegoría del ministro: "entonces la Natural / Ley reinaba, y como fue / natural error; erré, / mas hoy no temo desgracia, / reinando la Ley de Gracia, / de quien es trono mi fe" (Calderón, 1969a: 141). En este sentido, no debemos olvidar que, teológicamente, por la Gracia se perdonó el pecado del primer hombre; esto significa que el rey, al igual que Dios, debe ser misericordioso y perdonar sus faltas. Asimismo, la figura del valido está fortalecida en la alabanza de la reina: "mucho del hombre has debido a la atención y cuidado / con razón es tu privado" (Calderón, 1969a: 141).

Como podemos observar, en el texto están presentes los fundamentos de la concepción teocrática descendente del poder, opuesta a la ascendente, la cual predominó en la República Romana, donde el magistrado representaba al ciudadano y la fuerza de las leyes radicaban en la voluntad popular. En el plano alegórico, este auto sacramental dio un paso más, porque avanzó hacia la identificación del rey con Cristo, y de la reina con la Iglesia. Sin embargo, desde una perspectiva histórica, esta alegorización no nos debe conducir a pensar que el monarca tenía una naturaleza geminada, tal como lo discernió Ernst Kantorowicz (1985). En efecto, el historiador polaco consideraba a la persona real como mixta; es decir, humana por naturaleza y divina por la gracia conferida por la unción impartida en la ceremonia de consagración. Por el contrario, según lo advirtió el historiador español José Antonio Maravall, "los reyes, en España, no necesitaron asentar su poder en fórmulas 
teológicas, como el resto de los monarcas de la Alta Edad Media" (1970: 70). Prueba de esto es que se abolió temprano la unción real en el reino de Castilla y en el de León. No obstante, si bien se prescindió de la fundamentación sobrenatural, el poder se legitimó en la Biblia; es decir, en la versión del Texto Sagrado proporcionada por San Jerónimo.

En el plano discursivo, los conceptos de la teología política medieval se manifestaron a través de una figura retórica: la alegoría. Según Umberto Eco (2012) la sensibilidad medieval se caracterizó por una visión simbólicoalegórica del universo, porque se creía que "la cosa no es lo que parece, es un signo de otra cosa. La esperanza puede volver, por lo tanto, al mundo porque el mundo es el discurso que Dios hace al hombre" (2012: 89). Por esta razón, la alegoría era percibida a través del esfuerzo interpretativo. Este esfuerzo es real, porque el texto no tiene un solo sentido, tal como lo señalaba el antiguo brocardo latino: aliud dictitur, aliud demostratur. Por otra parte, debemos observar que desde el Romanticismo, en el siglo XVIII, se comenzó a distinguir la alegoría del simbolismo. En este sentido, en el texto de Calderón observamos un uso retórico de esta figura tal como fue teorizado por San Agustín. Él fue el primer autor que, en base a la doctrina estoica, fundó una teoría del signo. Así, distinguió los signos propios de los traspuestos, los cuales son "[...] signos intencionales, [...] pero en vez de ser usados de acuerdo con su finalidad inicial, se los desvía hacia un uso segundo" (Todorov, 1991: 60). A su vez, como lo discierne Bice Mortara Garavelli (1988), en esta figura se distingue la allegoria in verbis, de la allegoria infactis. La primera era identificada con el significado de los textos, mientras que la segunda con los hechos, entidades o personas, que se interpretaban como figuras de otros hechos, identidades o personas. Esta última, predomina en El nuevo Palacio del Retiro. Así, se manifiestan una serie de pares: el Palacio es la Jerusalén Triunfante; el duque de Olivares, valido del rey, es el Hombre Nuevo, quien ha sido redimido por la Gracia; el rey es Cristo; la reina, la Iglesia; etc. De este modo, las alegorías remiten a conceptos políticos esbozados en base a la interpretación de la Biblia.

Esta particularidad nos demuestra que, tanto en el mundo del Renacimiento como en el del Barroco se albergó una fuerte presencia de lo religioso. En este sentido, algunos pensadores, como el filósofo alemán Carl Smith y el historiador Ernst Kantorowicz, consideraron que no hubo una ruptura entre el Medievo y la Modernidad. Así, el filósofo germano, fuertemente cuestionado por su relación con el nazismo, consideró que los conceptos del derecho público moderno son conceptos teológicos secularizados; por ejemplo, la omnipotencia legislativa es el reverso de la concepción teológica sobre 
Dios. En este sentido, pensamos que si bien no podemos negar la pervivencia de lo teológico en los albores de la modernidad, debemos tener en cuenta que en el devenir histórico el proceso de secularización fue afianzándose.

\section{LA FORTUNA Y LA ACCIÓN HUMANA}

Para analizar el impacto de la obra del filósofo italiano en los lectores de la España del Siglo de Oro, debemos tener en cuenta que todo texto establece una relación con otros; es decir, con sus contemporáneos y con sus predecesores. Según H. Jauss (1981), en esta relación se manifiesta en un espacio común que él denominó como "el horizonte de expectativa de una obra", donde se puede comprobar si el texto respondió a las inquietudes de su época. En este sentido, podríamos afirmar que en la obra del pensador renacentista se plantearon las estrategias necesarias para adquirir y conservar el poder, independientemente de toda consideración jurídica, moral o religiosa, de acuerdo con el espíritu individualista que, según el historiador suizo J. Burckhardt (2008), caracterizó a la cultura del Renacimiento. De este modo, su doctrina planteó una ruptura con la tradición medieval, donde la política estaba subordinada a la teología. Sin embargo, como lo advierte J. A. Maravall, en la España de los Reyes Católicos "se encuentran antecedentes de lo que vulgarmente se denominó maquiavelismo" (Maravall, 1984: 198). En efecto, ya Ginés de Sepúlveda afirmó que en la guerra está permitido la simulación y el engaño; mientras que el modelo de gobernante esbozado en El Príncipe encontró su semejante en el accionar político del arzobispo toledano Rojas, quien fue capaz de utilizar, para sus fines, medios cuestionados tanto por la moral como por la religión.

Generalmente se afirma que la obra del filósofo italiano no fue lo suficientemente conocida en la España Moderna, al estar prohibida por la Inquisición. También por contarse con escasas traducciones. En este sentido, la historiadora Helena Puigdoménech (2008) señala que estas observaciones deben ser matizadas. Según ella, se debe tener en cuenta la independencia de la Inquisición Española de la Romana. En este sentido, en la península, en relación con su obra y otros temas, la Inquisición no siguió el mandato de Roma. Esta afirmación la podemos constatar al comprobar que, la obra del florentino, recién estuvo prohibida por el Índice del Cardenal Quiroga de 1583, mucho después de su interdicción por el Índice de Pablo IV, en 1558. Si bien es cierto que son escasas las traducciones, también debemos tener en cuenta que, durante el reinado de los Austrias, Italia formaba parte 
de la vida de España debido a las posesiones de la corona, como el reino de Nápoles y el ducado de Milán. Por esta razón, era común que los españoles de la época hablasen italiano como segunda lengua. Así, pues, la doctrina del influyente teórico político de la modernidad fue bien conocida por escritores, teólogos y filósofos españoles.

Uno de los temas más emblemáticos en la doctrina del filósofo renacentista es el de la acción humana ante la metamorfosis del mundo; es decir, los cambios que provoca la fortuna. En este sentido, abogó por oponer la acción humana a las mutaciones, solución opuesta a la propiciada por el estoicismo, que antepuso la integridad interior a los avatares de la fortuna. En efecto, el estoicismo de Séneca abogó por la supremacía moral del sabio, pues jamás el hombre egregio se abatirá ante la mala fortuna, porque "¿qué cosa hay que pueda estar encima de aquel que está sobre la fortuna?" (Séneca, 1965: 35).

Estos postulados se manifiestan en el drama calderoniano Saber del mal y del bien, cuyo trama argumental gira en torno a la caída del poderoso conde Pedro de Lara, privado del rey Alfonso VII de Castila. Este noble, quien coronó al rey en su niñez y encarceló a su madre, la famosa doña Urraca, por sus intrigas. Desde el comienzo de la obra, el valido del rey presiente su desgracia, pues en la corte está presente la envidia, "monstruo infame, / disimulado en lisonjas / como entre flores el áspid" (Calderón, 1969b: 222). A su vez, el privado sabe que la deidad que rige el destino de los hombres arremete con más fuerza en las cumbres, "porque el rayo y la fortuna / su mayor efecto hace / en la eminencia del monte / que en la humildad de los valles" (Calderón, 1969b: 223). En la soledad del poder, el conde encuentra un amigo en Álvaro de Viseo, noble portugués víctima de la fortuna, hombre tan desdichado, quien "la cara no conoce / del bien" (Calderón, 1969b: 216). Él es un espejo del poderoso, quien es consciente de su realidad: "quiero tener hoy en vos / un espejo en que mirarme” (Calderón, 1969b: 224).

El conde no es un político sin escrúpulos, sino un leal servidor del rey, víctima de las rivalidades de la corte. Por esta razón, cuando cae en desgracia esgrime como defensa, su pasado ejemplar: “(...) en ausencia / vuestra, a ser más atrevido, / quisieron hacerme Rey; / y, quizá, Señor, los mismos / que hoy quieren hacerme nada" (Calderón, 1969b: 233). En la caída del valido podemos observar que se entrelazan la moral estoica con las enseñanzas del Libro de Job, texto bíblico que narra los sufrimientos del justo.

Frente a las intrigas de los cortesanos envidiosos, el conde decide partir al destierro, camino amargo, donde sólo encuentra amparo en Álvaro de Viseo, quien atinadamente lo consuela: “(...) mientras más bajéis, más fuer- 
zas / cobráis, mas valor, más brío / para levantaros solo" (Calderón, 1969b: 234). Como podemos observar, el conde frente a la adversidad exterior se repliega en su interioridad. Ante este repliegue, la fortuna le devuelve el favor del rey, tal como Dios premió a Job por soportar heroicamente las tribulaciones. Sin embargo, el rey siempre creyó en la inocencia del conde: "Si hubiera, Álvaro, creído / que traidor el conde fue, / no hubiera el conde quedado / con vida. Yo llegué / a desengañarle sólo de que pudiera sin él / vivir” (Calderón, 1969b: 235). Así, aplicó un castigo correctivo, para que el noble “desengaña su arrogancia, / escarmiente su altivez" (Calderón, 1969: 236).

Ante tantos avatares injustos, Álvaro de Viseo anhela la paz retirada del sabio estoico, que ha firmado la paz con la terrible deidad: "[... ] y es, pues que estoy / contigo en paz desde hoy, / de mi memoria el olvido; / déjame en aqueste estado, / ni envidioso / donde ni aflija al dichoso / ni consuele al desdichado" (Calderón, 1969b: 236). Al recuperar la gracia real, el conde manifiesta su sabiduría acrisolada por el sufrimiento: "[...] y me quedaré a servir / con mayores esperanzas / de que sabré, pues ya supe / del bien y del mal" (Calderón, 1969b: 242). Así, el conde recuperó la gracia al ser expulsado de la corte. A su vez, esta expulsión nos remite a otra: la de Adán del Paraíso Celestial, pues violó la interdicción emanada de Dios de comer el fruto prohibido, el de la ciencia del bien y del mal. De este pecado fue redimido por Cristo, la Ley de la Gracia; como el valido, por la gracia del monarca. De este modo se evidencia el fundamento que, como ya lo mencionáramos, en la Edad Media, el vínculo entre el rey y Dios se estableció por medio de la Gracia. En este sentido, también por la gracia, el soberano entablaba el vínculo con sus súbditos. A su vez, desde la filosofía estoica, saber del mal y del bien era poder resistir a los embates de la fortuna adversa.

Desde una perspectiva retórica, se intenta persuadir sobre la preeminencia de la ética estoica no solo a través de razonamientos, sino también apelando a los afectos. Al respecto, debemos tener en cuenta que, en algunas retóricas del Siglo de Oro, como la de Miguel de Salinas, fraile de la orden de los Jerónimos, está presente una teorización sobre los afectos, según el modelo de la retórica aristotélica, a lo que él denominó como persuasión interior. Así, el religioso afirmó que "no el asombro, la simple información, o el entretenimiento es lo que se busca; sino provocar un determinado movimiento del alma en el que escucha o en el que lee" (Casas, 1980: 32). Así definió lo afectivo como "un movimiento o perturbación que más propiamente decimos las pasiones del ánima, porque según las mudanzas que se ofrecen, así se inclinan a dolor, alegría, misericordia, amor, odio, etc" (1980: 156). En este sentido, las vicisitudes del valido nos provocan un sentimiento 
de compasión, pero también de admiración. De este modo, se nos señala el valor de la fortaleza interior, para trascender la desgracia, tal como lo predicaba la ética estoica.

El pensamiento de Nicolás Maquiavelo discrepa con estoicismo grecolatino. En efecto, el filósofo florentino opuso la acción a la fortaleza interior. Según él, la audacia y la determinación son los atributos esenciales en la lucha contra los avatares de la fortuna, pues ésta es artífice sólo de la mitad de las acciones que construyen nuestro destino. Así, mediante la metáfora de la mujer, de marcado sesgo misógino, el autor de El Príncipe, como ya lo mencionamos, apela a la acción, a la audacia, porque: "[...] es mejor ser impetuoso que precavido, porque la fortuna es mujer, y si se quiere tenerla sumisa, resulta necesario castigarla y golpearla” (Maquiavelo, 2008: 202).

El estoico se sobreponía a los caprichos de la fortuna con su integridad interior. Por eso admiró la libertad del sabio: "[...] suelto y dueño de sí y más elevado que los otros. ¿Qué cosa hay que pueda estar encima de aquel que está por encima de la fortuna” (Séneca,1965: 35). Así, pues, sólo el sabio, quien ha aprendido a dominarse, puede trascender la inestabilidad de la existencia, poblada de incertidumbre.

En relación a la fortuna, el hombre moderno, como Hamlet se preguntó: "[...] ¿Será más noble sufrir en silencio / los dardos y flechas de la atroz fortuna, / o levantarse en armas contra un mar de infortunios" (Shakespeare, 2007: 71). En la duda del atormentado príncipe de Dinamarca encontramos los dos caminos que, en los albores de la modernidad, el hombre podía escoger. En efecto, por un lado para "sufrir en silencio" las mutaciones del mundo se necesitaba la fortaleza interior predicada por los estoicos, por otro que el "levantarse en armas" llevaba a la acción, camino propiciado por Maquiavelo, se requería determinación.

Fundamentalmente, la diosa, según Séneca, arremetía con más fuerza en las cumbres: "[...] los bienes más grandes se poseen con recelo, y ninguna fortuna ha de inspirar más desconfianza que la mejor" (1965: 57). La diferencia entre ambas doctrinas radicaba en que, al reubicar Maquiavelo la cuestión de la fortuna en el terreno de la política, se canceló toda cuestión de la entereza interior, enfatizada por la tradición estoica que la oponía a la fortuna exterior. Asimismo, la prudencia, que también fue predicada por los estoicos, pasó a ser: "[...] una ancilla (sirvienta) de las pasiones y de la ambición, y en la que la audacia y la determinación se erigen en claves fundamentales de la lucha por el poder individual" (Forte Monge, 2011: 95).

Si la temida deidad prefería las cumbres, entonces es allí, en el poder, donde se nos ofrece la mejor pintura de sus mutaciones. En este sentido, el 
drama de Calderón, La gran Cenobia, nos muestra un escenario privilegiado para analizar las vicisitudes que provocaba en la vida de los hombres. En esta obra, Aureliano, militar que se había retirado a los montes para consolarse de su frustrada ambición, recibe el cetro imperial como regalo. Sin embargo, él lo atribuye a sus méritos: "[...] si me ofrece la fortuna / el bien, ¡ por qué no lo gozo? / ¿qué aguardo pues le merezco? / ¿qué dudo, pues le conozco?” (Calderón, 1969c: 73). Su ascenso fue la contracara de la desgracia de Decio, general derrotado por Cenobia, la gran reina de oriente, quien en su caída comprendió: "[...] ¡qué vida habrá segura / en donde vence la fuerza y la hermosura" (Calderón, 1969c: 75).

Además, Aureliano y Decio están separados por notables diferencias: humildad / soberbia; / crueldad, justicia / tiranía / clemencia; entre otras virtudes y defectos. Fundamentalmente, ambos se diferencian en sus valoraciones sobre la fortuna. En efecto, mientras que el general derrotado la venera, el soberbio monarca la desconoce: "[...] ni la temo, ni respeto; / témela tú, que en efecto / es la fortuna mujer" (Calderón, 1969c: 76). A su vez, Decio es lo opuesto de Liodoro, el infante postergado, quien en pos de su ambición, el trono, traicionó a Cenobia, su soberana. Así observamos otro par: lealtad / traición. Por lealtad a Roma, el general rechazó comandar el ejército oriental: "[...] pues he de ser / contra mi patria traidor? / Contra Aureliano, bien puedo, / como ofendido; mas no /contra los míos" (Calderón, 1969c: 81). Esta lealtad se diferenció del infame ardid del infante, pues llevada a cabo su traición pese a las sabias advertencias de Cenobia: "[...] y no es posible alcanzar / honra por infames modos / pues el que más alto estuvo / a ser más notado viene / cuando el mismo honor que tiene / dice la infamia que tuvo" (Calderón, 1969c: 83).

A través de la traición, Aureliano obtuvo a Cenobia, su trofeo más preciado. De esta manera, la rueda de la fortuna dio otro giro, tal como lo reconoció en su desgracia la reina: "[...] Aureliano, las venganzas / de la fortuna son éstas, / que ni son grandezas tuyas, / ni culpas mías" (Calderón, 1969c: 93). En el mismo sentido reflexionó Decio, Junto a Astrea: “[...] A Roma llegas a tiempo / de ver la mayor tragedia que en el teatro del mundo / la fortuna representa" (Calderón, 1969c: 92). Pese a estas mudanzas, el emperador persistió en desconocerla: "[...] O no osa ya la fortuna / o me teme o me respeta. / Ni la estimo ni la aprecio" (Calderón, 1969c: 94). Esta necedad, lo acompañó hasta el regicidio. Así, en su agónico final reclamó al cielo: “[...]Dioses. ¡¿Esto permitís? / ¡Esto sufrís? ¿Esto hacéis?” (Calderón, 1969c: 100).

En el plano discursivo, la controversia sobre la fortuna se manifestó a 
través de una disputa, la cual nos conduce a la metodología empleada por los jesuitas en sus colegios: la Ratio Studiorum, en la que se formó Calderón. Este método aspiraba a "conseguir la identidad ideológica entre una disciplina escolar, una disciplina de pensamiento y una disciplina del lenguaje" (Rodríguez Cuadros, 1997: 39). De este modo, la Disputatio fue una estrategia didáctica para dilucidar conceptos filosóficos y teológicos, tal como en el texto se examinan los postulados de la ética estoica.

Con la muerte del tiránico emperador se restableció el orden. Los nuevos soberanos, Decio y Cenobia, poseen la prudencia, la sabiduría y la humildad. Estos, pues, son los atributos que han de caracterizar al buen gobernante, los cuales estuvieron ausentes en Aureliano, quien, a diferencia de Segismundo, no alcanzó su conversión. Por esta razón, en la obra, se justificó el regicidio: "[...] Cesar nuestro, por habernos / librado de un tirano ciñe el sagrado laurel, Decio" (Calderón, 1969c: 100-101).

Esta argumentación no fue más que un eco de la doctrina del padre Mariana sobre el regicidio, cuyos textos leyó Calderón en el Colegio Imperial de los Jesuitas, donde se formó.

\section{CONCLUSIÓN}

El advenimiento de la modernidad no significó una ruptura con la tradición, por el contrario, en la filosofía política ésta fue reexaminada a la luz del realismo político moderno, basado en la doctrina de Nicolás Maquiavelo, cuyo pensamiento fue bien conocido en la España del Siglo de Oro.

En el teatro de Pedro Calderón de la Barca nos encontramos que la tradición política medieval, basada, fundamentalmente, en conceptos teológicos, legitimó en el auto sacramental El nuevo Palacio del Retiro la autoridad del rey, Felipe IV, y de su valido, el Conde-Duque de Olivares. A su vez, tanto en Saber del mal y del bien, como en La Gran Cenobia, el pensamiento estoico, fuertemente ligado con los Padres de la Iglesia, está en relación dialéctica con el de Nicolás Maquiavelo. Esta relación culmina en una síntesis ética, la cual caracterizó al pensamiento político de Pedro Calderón de la Barca.

Si bien el proceso de secularización iniciado en la modernidad culminó en las democracias modernas, donde el poder va en un sentido ascendente, es decir del pueblo a sus representantes, el debate entre la ética y el poder sigue vigente. Sin embargo, el hombre contemporáneo aprendió, tras el advenimiento de los totalitarismos, que ninguna razón de Estado justifica la violación de derechos esenciales. 


\section{REFERENCIAS}

Berman, Marshall. (2008). Todo lo sólido se desvanece en el aire. La experiencia de la modernidad. Madrid: Siglo Veintiuno.

Biblia. (1980). Madrid: Ediciones Paulinas.

Burckhardt, Jacob. (2008). La cultura del renacimiento en Italia. Buenos Aires: Akal.

Calderón de la Barca, Pedro. (1969a). El nuevo Palacio del Retiro, en Obras Completas. Madrid: Aguilar. . (1969b). Saber del mal y del bien, en Obras Completas. Madrid: Aguilar.

. (1969c). La gran Cenobia, en Obras Completas. Madrid: Aguilar.

Casas, Elena (comp). (1980). La retórica en España. Madrid: Editorial Nacional.

Eco, Umberto. (2012). Arte y belleza en la estética medieval. Buenos Aires: Edit. De Bolsillo.

Forte Monge, Juan Manuel. (2011). Estudio introductorio a las obras de Maquiavelo. Madrid: Gredos.

Foucault, Michel. (1996). ¿Qué es la Ilustración? Madrid: Ediciones La Piqueta.

Habermas, Jürgen. (2012). El discurso filosófico de la modernidad. Buenos Aires: Editorial.

Jauss, Hans. (1981). Estética de la recepción y comunicación literaria. Punto de Vista, 12, 34-40.

Kantorowicz, Ernst. (1985). Los dos cuerpos del rey. Madrid: Alianza.

Maquiavelo, Nicolás. 2008. El Principe. Buenos Aires: Losada.

Maravall, José A. (1970). El proceso de secularización en la España de los Austrias. Revista de Occidente, 88, 61-99.

(1984). Estudios de historia del pensamiento español. Madrid: Ediciones de Cultura Hispánica.

Mortara Garavelli, Bice. (1988). Manual de Retórica. Madrid: Cátedra.

Puigdoménech, Helena. (2008). Maquiavelo y Maquiavelismo en España. Siglos XVI y XVII. En Forte Juan Manuel y López Álvarez, Pablo (eds.), Maquiavelismo y antimaquiavelismo en la cultura española de los siglos XVI y XVII (pp. 41-60). Madrid: Biblioteca Nueva.

Regalado, Antonio. (1995). Calderón. Los orígenes de la modernidad en la España del Siglo de Oro. Madrid: Destino.

Rodríguez Cuadros, Evangelina. (1997). Introducción. En Pedro Calderón de la Barca, La vida es sueño. Madrid: Espasa Calpe. 
Séneca, Lucio A. (1965). De la brevedad de la vida. Madrid: Aguilar.

Shakespeare, William. (2007). Hamlet. Rolando Costa Picazo (trad.). Buenos Aires: Ediciones Colihue.

Strauss, Leo. (2006). La filosofía política de Hobbes. Su fundamento y su génesis. México: Fondo de Cultura Económica.

Todorov, Tzvetan. (1991). Teorías del símbolo. Caracas: Monte Ávila Editores.

Ullmann, Walter. (2003). Escritos sobre Teoría Politica Medieval. Buenos Aires: Eudeba. 